\title{
Gender differences in dispensed analgesics in Sweden during 2006-20I5 - an observational, nationwide, whole-population study
}

This article was published in the following Dove Press journal: International Journal of Women's Health

\author{
Emmanuel Bäckryd \\ Pain and Rehabilitation Centre, \\ Department of Medical and Health \\ Sciences, Linköping University, \\ Linköping, Sweden
}

\begin{abstract}
Introduction: A potentially illuminating way of looking at gender differences in health and disease is to study differences in drug utilization. The aim of this study was to describe gender differences in dispensed analgesics (including nonsteroidal anti-inflammatory drugs [NSAIDs]) in Sweden during 2006-2015.
\end{abstract}

Materials and Methods: The Swedish Board of Health and Welfare holds an open, Anatomical Therapeutic Chemical (ATC)-based statistical database containing aggregated data on all dispensed prescription drugs in Swedish pharmacies since 2006. The database is searchable according to sex, age (5-year intervals), and Swedish regions.

Results: Nationwide, whole-population information was retrieved for all ATC codes at the second level for individuals $\geq 20$ years of age, focusing on sex-related differences. More indepth analyses were made for analgesics, including NSAIDs. Descriptive statistics were used. Gender differences in drug prescription are pervasive in Sweden; the yearly prevalence in 2015 was higher in women for 72 out of 84 ATC groups (not adjusted for age). Analgesics, including NSAIDs, were more commonly used by women in all age groups. Gender differences were sustained over time (2006-2015) and were particularly striking for triptans. For both men and women, the yearly prevalence of opioids was stable during 2006-2015, whereas it increased for paracetamol and decreased for NSAIDs. The increase in paracetamol prescription was most noticeable for young females, and the decrease in NSAID prescription was largest in older patients (irrespective of sex).

Conclusion: Gender differences in the use of analgesics probably mirror the higher prevalence of chronic pain in women.

Keywords: drugs, medicines, opioids, sex, nonsteroidal anti-inflammatory drugs, NSAIDs, paracetamol, acetaminophen, triptans

\section{Introduction}

Sex and gender issues are important to consider in a wide range of medical conditions, including the fields of cardiovascular medicine, ${ }^{1,2}$ airway diseases, ${ }^{3}$ gastroenterology and hepatology, nephrology, endocrinology, hematology, and neurology. ${ }^{4}$ Psychiatry is another area with important gender differences. Depression is, for instance, more common in females, ${ }^{5}$ and there is a need to better understand depression in males. ${ }^{4}$ However, the impact of sex and gender is often neglected in the medical field, ${ }^{6,7}$ and most guidelines do not include even well-known sex differences. ${ }^{8}$ This may have consequences in outcome and treatment effects. ${ }^{8}$

An area where gender differences are particularly striking is pain medicine. Women have a much higher prevalence of many pain disorders, including migraine,
Correspondence: Emmanuel Bäckryd Pain and Rehabilitation Medicine, Department of Medical and Health Sciences, Linköping University, Linköping Brigadgatan 22, SE-58I 85, Sweden Tel +46 I0 I03 366I Email emmanuel.backryd@ regionostergotland.se 
fibromyalgia, irritable bowel syndrome, and temporomandibular joint disorders. ${ }^{9}$ Recent evidence suggests that women's higher pain sensitivity may be explained, at least in part, by neuroimmune differences. ${ }^{10,11}$ In addition to biologic differences in pain processing, for example, putative differences in neural structures ${ }^{9,12}$ or the pain modulatory effect of sex hormones, ${ }^{9,12,13}$ psychological and sociocultural mechanisms are also thought to be important. ${ }^{12,14}$ Sex and gender differences are also important pharmacologically, for example, concerning pharmacodynamics and pharmacokinetics, ${ }^{4}$ opioid pharmacology might, for instance, be influenced by sex. ${ }^{15}$

Pain medicine has been heavily influenced by the biopsychosocial (BPS) model launched by George L Engel in a famous paper published four decades ago. ${ }^{16,17}$ In the words of Borrell-Carrio et al, the BPS model "is a way of understanding how suffering, disease, and illness are affected by multiple levels of organization, from the societal to the molecular". ${ }^{17}$ This applies very much not only to pain medicine but also arguably to gender medicine. ${ }^{4,18}$ Established semantics mirror the broadness of the area, with "sex" being a biologic descriptor whereas "gender" is a social science descriptor. ${ }^{18}$ In this paper, both terms will be used more or less interchangeably, in accordance with a "holistic" BPS way of thinking.

A potentially illuminating way of looking at gender differences in health and disease is to study differences in drug utilization. Studies have shown that females generally use medicines (not least psychotropic drugs and analgesics) more often than males, ${ }^{19-22}$ one important exception being cardiovascular drugs. ${ }^{23}$ The aim of this pain medicine-oriented study is to describe gender differences in dispensed systemic analgesics in Sweden from 2006 to 2015. In order to relate the findings to other drugs, a "top down" approach was chosen, that is, looking first at all Anatomic Therapeutic Chemical (ATC) groups for 2015 and then narrowing down the analysis to analgesics (including age strata and time trends).

\section{Materials and methods Drug classification system and defined daily dose}

The World Health Organization Collaborating Centre for drug statistics methodology in Oslo, Norway, oversees the ATC classification system for prescription drugs, as well as the related defined daily dose (DDD) measuring unit. ${ }^{24}$ DDD is the assumed average maintenance dose per day for a drug used for its main indication in adults, and it provides a fixed unit of measurement independent of dosage form (eg, tablet strength). ATC and DDD are important tools for international drug utilization research, and the 2015 version was used..$^{22,24}$

\section{Materials}

Based on the Swedish Prescribed Drug Register, ${ }^{25,26}$ the Swedish Board of Health and Welfare holds an open, searchable statistical database containing aggregated data on all dispensed prescription drugs in Swedish pharmacies since 2006. This publicly available database is structured according to the ATC classification system, and available data are as follows: 1) total number of patients dispensed at least one prescription per year; 2) yearly prevalence (ie, number of individuals being dispensed at least one prescription per year, "patients per 1,000 inhabitants"); 3) total number of dispensed prescriptions; 4) number of dispensed prescriptions per 1,000 inhabitants; 5) total amount of DDD; and 6) DDD per 1,000 inhabitants. The database is searchable according to sex, age (5-year intervals), and Swedish regions.

In this study, only individuals $\geq 20$ years of age were studied at a national level, focusing on sex-related differences in dispensed analgesics (ATC code N02), including systemic nonsteroidal anti-inflammatory drugs (NSAIDs; ATC code M01A). Tricyclics and gabapentinoids are firstline drugs for the treatment of neuropathic pain $;{ }^{27}$ however, these drugs were not included in this study due to the impossibility of differentiating pain-related prescription from other indications.

\section{Statistical analysis}

To analyze these aggregated, whole-population data with nationwide coverage, descriptive statistics was used (IBM SPPS version 23 and Excel 2013). Based on the information available in the open drug statistical database of the Swedish Board of Health and Welfare, mean DDD per treated patient/ year and mean number of prescriptions per treated patient/ year were also calculated when appropriate.

\section{Ethics}

Data in this study were retrieved from a database that contains publicly available, aggregated, nationwide, wholepopulation information provided by the Swedish authorities. Hence, retrieving informed consent was neither possible nor necessary.

\section{Results Yearly prevalence for all ATC codes in 2015}

Theyearly prevalenceforall ATC codesat thesecondlevelinSweden 2015 is summarized in Supplementary materials, Table S1. The yearly prevalence (patients per 1,000 inhabitants) was higher in females in 72 out of 84 ATC codes. Anti-inflammatory products (M01) and analgesics (N02) were among the 
most prevalent ATC codes, and both had a female/male ratio $>1$ for yearly prevalence: anti-inflammatory products (M01) had a yearly prevalence of 147 in females and 115 in males, and the corresponding figures for analgesics (N02) were 241 and 154, respectively. As can be seen in Table S1, the yearly prevalence of psycholeptics (N05) and psychoanaleptics (N06) was also among the highest, with female/ male ratio $>1$. Given the extensive psychiatric comorbidity in chronic pain conditions (including insomnia), it was decided to include these two groups when looking at the next level in the ATC hierarchy.

\section{Analgesics (including NSAIDs), psycholeptics, and psychoanaleptics in 2015}

Looking at the next level in the ATC hierarchy, 10 subgroups were studied further. These are depicted in Figure 1; the female/male ratios of yearly prevalence in 2015 were (in falling order from the highest to the lowest) as follows:

- 3.65 for antimigraine drugs (N02C)

- 1.87 for antidepressants (N06A)

- 1.79 for anxiolytics (N05B)
- 1.73 for hypnotics and sedatives (N05C)

- 1.66 for paracetamol (N02BE01)

- 1.52 for anti-dementia drugs (N06D)

- 1.34 for opioids (N02A)

- 1.28 for NSAIDs (M01A)

- 1.19 for antipsychotics (N05A)

- 0.93 for psychostimulants (N06B).

Hence, women had higher yearly prevalence for 9 out of 10 subgroups. With the exception of antimigraine drugs, the female/male ratios were higher for antidepressants, anxiolytics, and hypnotics and sedatives than for analgesics.

\section{Analgesics, including NSAIDs}

Analgesics (N02), including NSAIDs (M01A), were studied further for 2015. Only drugs with a yearly prevalence of at least $0.1 \%$ (men and women counted together) were included. The results are summarized in Table 1.

When comparing the yearly prevalence (patients per 1,000 inhabitants) with the mean dose per treated patient (DDD/ patient/year), the following were found:

- For paracetamol (N02BE01), the female/male ratio for yearly prevalence was 1.66 , whereas the female/male

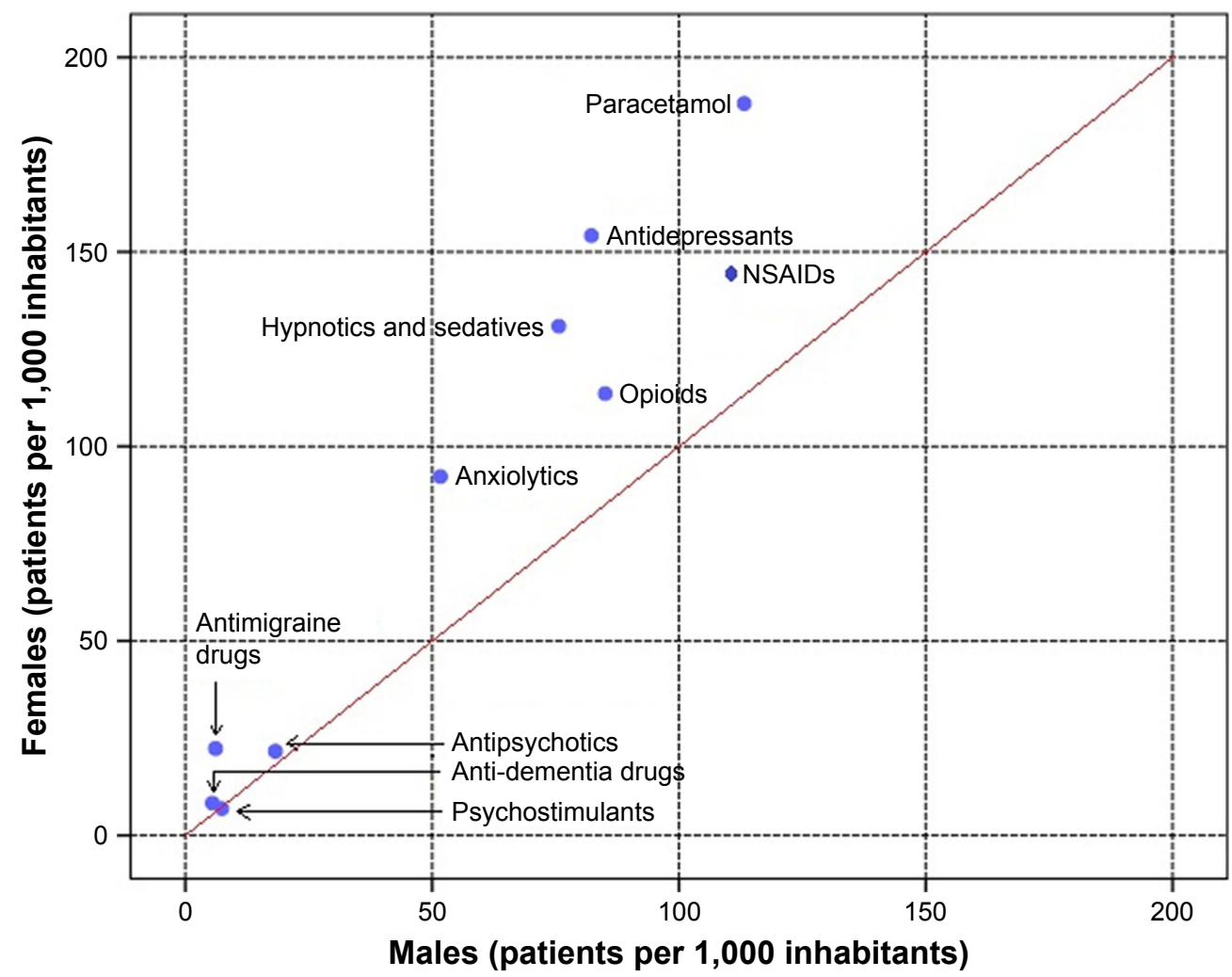

Figure I Nationwide, whole-population yearly prevalence in Sweden in 2015 (patients per 1,000 inhabitants) for 10 ATC subgroups, scatter plot of males vs females. Notes: The red "gender equality line" signifies perfect gender equality in yearly prevalence. Note that the gender equality line is by no means prescriptive or normative; it is descriptive. Corresponding ATC codes: anti-dementia drugs, N06D; antidepressants, N06A; antimigraine drugs, N02C; antipsychotics, N05A; anxiolytics, N05B; hypnotics and sedatives, N05C; NSAIDs, M0IA; opioids, N02A; paracetamol, N02BE0I; psychostimulants, N06B.

Abbreviations: ATC, anatomical therapeutic chemical; NSAIDs, nonsteroidal anti-inflammatory drugs. 
Table I Dispensed prescription data in Sweden 2015 for the most common analgesics, including nonsteroidal anti-inflammatory drugs

\begin{tabular}{|c|c|c|c|c|c|c|c|c|c|c|}
\hline \multirow[t]{2}{*}{ Drug and ATC code } & \multicolumn{2}{|c|}{$\begin{array}{l}\text { Patients per } \\
\text { I,000 inhabitants }\end{array}$} & \multicolumn{2}{|c|}{$\begin{array}{l}\text { Prescriptions per } \\
\text { I,000 inhabitants }\end{array}$} & \multicolumn{2}{|c|}{$\begin{array}{l}\text { DDD per } 1,000 \\
\text { inhabitants }\end{array}$} & \multicolumn{2}{|c|}{ DDD per patient } & \multicolumn{2}{|c|}{$\begin{array}{l}\text { Prescriptions } \\
\text { per patient }\end{array}$} \\
\hline & Females & Males & Females & Males & Females & Males & Females & Males & Females & Males \\
\hline M0IAB05 diclofenac & 43.6 & 43.75 & 72.43 & 69.62 & 2,328 & 2,306 & 53.4 & 52.7 & 1.7 & 1.6 \\
\hline M0IAB55 diclofenac, comb & 2.49 & 1.86 & 5.22 & 3.5 & 290 & 189 & 116.6 & 101.9 & 2.1 & 1.9 \\
\hline MOIAEOI ibuprofen & 26.99 & $|5.3|$ & 53.47 & 27.39 & 2,010 & 1,020 & 74.5 & 66.7 & 2.0 & 1.8 \\
\hline MOIAE02 naproxen & 61.6 & 45.9 & 97.39 & 68.25 & 5,757 & 4,027 & 93.5 & 87.8 & 1.6 & 1.5 \\
\hline MOIAE03 ketoprofen & 8.5 & 4.98 & 17.64 & 10.64 & 1,559 & 1,032 & 183.4 & 207.4 & 2.1 & 2.1 \\
\hline MOIAEI4 dexibuprofen & 2.93 & 2.15 & 5.62 & 3.69 & 208 & 130 & 71.2 & 60.5 & 1.9 & 1.7 \\
\hline MOIAHOI celecoxib & 2.74 & 1.52 & 5.7 & 2.97 & 305 & 157 & 111.5 & 103.1 & 2.1 & 1.9 \\
\hline MOIAH05 etoricoxib & 12.47 & 9.26 & 24.75 & 17.48 & 1,238 & 873 & 99.3 & 94.3 & 2.0 & 1.9 \\
\hline MOIAXOI nabumetone & 1.75 & 0.92 & 4.3 & 1.94 & 250 & 108 & 143.2 & 118.0 & 2.5 & 2.1 \\
\hline M0IAX05 glucosamine & 3.15 & 1.64 & 9.46 & 4.31 & 445 & 232 & $14 \mid .5$ & 141.9 & 3.0 & 2.6 \\
\hline N02AA0I morphine & 12.35 & 8.32 & 65.51 & 35.97 & 400 & 291 & 32.4 & 35.0 & 5.3 & 4.3 \\
\hline N02AA05 oxycodone & 36.47 & 28.38 & 163.52 & 111.45 & 887 & 766 & 24.3 & 27.0 & 4.5 & 3.9 \\
\hline N02AA55 oxycodone and naloxone & 4.56 & 3.94 & 13.77 & 9.66 & 90 & 72 & 19.8 & 18.4 & 3.0 & 2.4 \\
\hline N02AA59 codeine, comb & 47.56 & 35.42 & 153.1 & 99.55 & 3,924 & 2,602 & 82.5 & 73.5 & 3.2 & 2.8 \\
\hline N02ABOI ketobemidone & 1.5 & 0.79 & 5.64 & 2.72 & 28 & 13 & 19.2 & 17.7 & 3.8 & 3.4 \\
\hline N02AB03 fentanyl & 3.69 & 2.1 & 19.68 & 10.11 & 618 & 341 & 167.6 & 162.7 & 5.3 & 4.8 \\
\hline N02AE0I buprenorphine & 8.97 & 3.6 & 35.06 & 14.93 & 411 & 201 & 45.9 & 55.9 & 3.9 & 4.2 \\
\hline N02AG0I morphine and antispasm & 2.86 & 2.16 & 6.24 & 3.39 & I & I & 0.5 & 0.48 & 2.2 & 1.6 \\
\hline N02AX02 tramadol & 24.87 & 19.65 & 104.5 & 78.56 & $2,|5|$ & $\mathrm{I}, 734$ & 86.5 & 88.3 & 4.2 & 4.0 \\
\hline N02BE0I paracetamol & 188.13 & 113.22 & 847.55 & 418.33 & 20,440 & 10,473 & 108.7 & 92.5 & 4.5 & 3.7 \\
\hline N02CCOI sumatriptan & 14.78 & 4.17 & 54.93 & $|5.8|$ & $\mathrm{I}, 008$ & 299 & 68.2 & 71.9 & 3.7 & 3.8 \\
\hline N02CC03 zolmitriptan & 4.7 & 1.14 & 21.1 & 5.06 & 446 & 117 & 95.1 & 102.8 & 4.5 & 4.4 \\
\hline N02CC04 rizatriptan & 2.5 & 0.56 & 9.3 & 2.12 & 135 & 32 & 54.0 & 58.7 & 3.7 & 3.8 \\
\hline
\end{tabular}

Abbreviations: antispasm, antispasmodics; ATC, anatomical therapeutic chemical; comb, combinations; DDD, defined daily dose.

ratio for DDD/patient/year was 1.18 (based on data presented in Table 1).

- For opioids as a group (N02A), the yearly prevalence in females was 113.6 and in males was 85.1 (N02A group data are not shown in Table 1), and the female/male ratio for yearly prevalence was, therefore, 1.34. The female/ male ratio for DDD/patient/year for the different opioids listed in Table 1 ranged from 0.82 to 1.12 . Hence, more females than males were prescribed opioids, but the mean dose per patient and year was not consistently higher for females.

- For NSAIDs as a group (M01A), the yearly prevalence was 146.5 in females and 115.4 in males, and the female/ male ratio for yearly prevalence was, therefore, 1.28 . The female/male ratio for DDD/patient/year for the different NSAIDs listed in Table 1 ranged from 0.88 to 1.21 . Hence, as for opioids, more females than males were prescribed NSAIDs, but the mean dose per patient and year was not consistently higher for females.

- For 5HT1 agonists/triptans as a group (N02CC), the yearly prevalence was 21.1 in females and 5.6 in males, and the female/male ratio for yearly prevalence was 3.75. The female/male ratio for DDD/patient/year for the most common triptans listed in Table 1 ranged from 0.92 to
0.95. Hence, more females than males were prescribed triptans, but the mean dose per patient and year was slightly lower in females.

Next, the age distribution of yearly prevalence in 2015 was studied for males and females. For opioids (N02A; Figure 2A) and paracetamol (N02BE01; Figure 2B), the yearly prevalence for both males and females increased with age, with the highest prevalence recorded in the highest age group ( $>85$ years of age). In contrast, for 5HT1 agonists/ triptans (N02CC), the yearly prevalence in both males and females peaked at 50-54 years of age (Figure 2C). For NSAIDs (M01A), the age distribution was similar to 5HT1 agonists/triptans (N02CC) for both men and women (Figure 2D). For all drug classes depicted in Figure 2, the female/male ratios were $>1$ for all age groups (lines in Figure 2A-D).

Finally, time trends for yearly prevalence during 20062015 were investigated for males and females (Figure 3). The yearly prevalence for opioids (N02A) was stable over time, with perhaps a slight diminution of gender differences toward the end of the period (Figure 3A). Notably, the yearly prevalence of NSAIDs (M01A) diminished for both males and females during 2006-2015, whereas it increased for paracetamol (N02BE01; Figure 3C and D). For paracetamol 


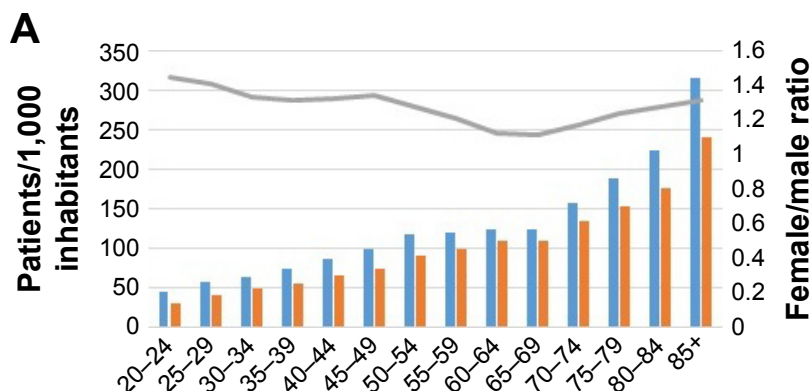

Age groups

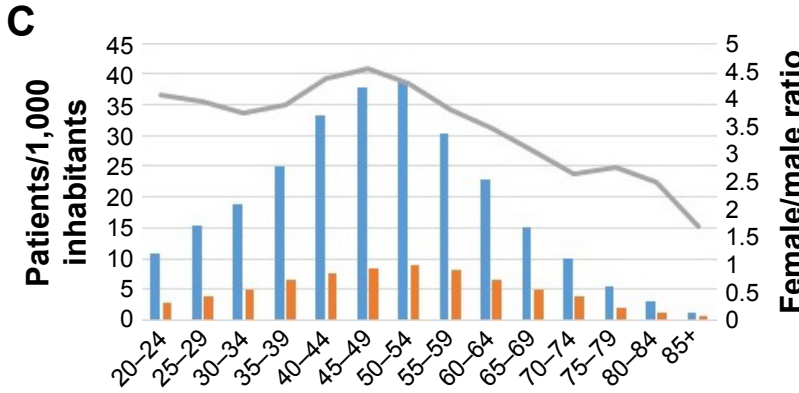

Age groups

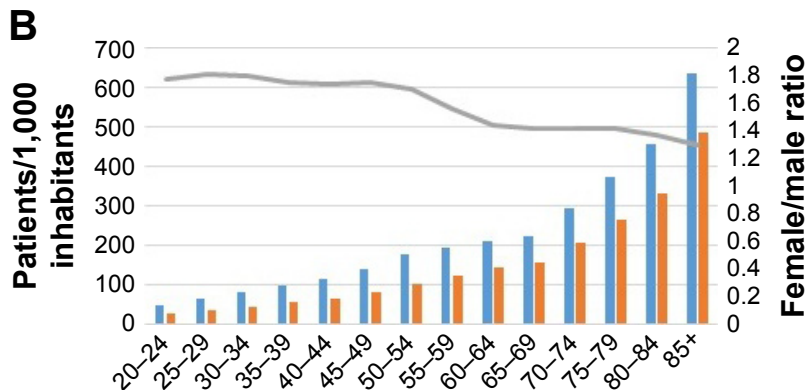

Age groups

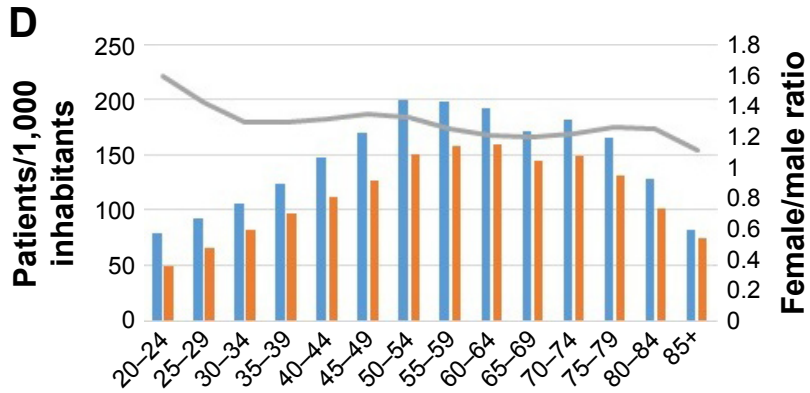

Age groups

Figure 2 Yearly prevalence in 2015 by age group and sex for (A) opioids (N02A), (B) paracetamol (N02BEOI), (C) 5HTI agonists/triptans (N02CC), and (D) NSAIDs (M0IA). Abbreviation: NSAIDs, nonsteroidal anti-inflammatory drugs.
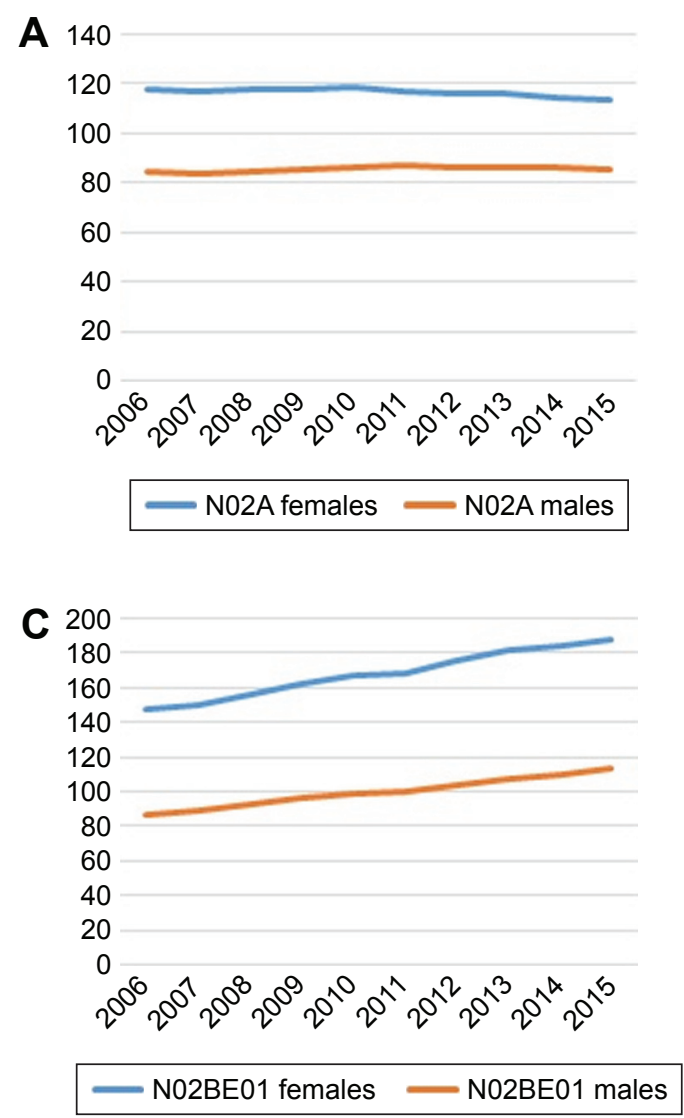

B 25

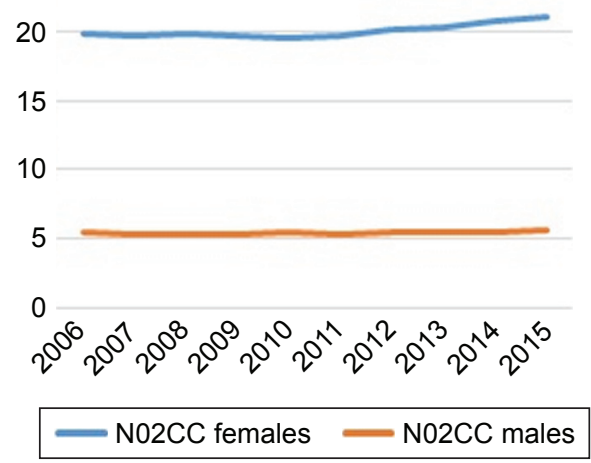

D 250

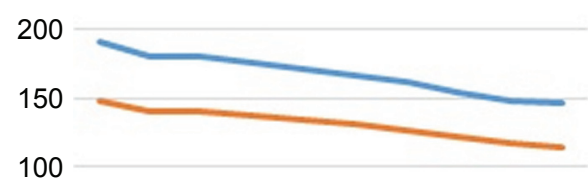

50

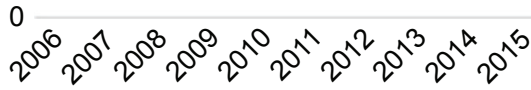

M01A females M01A males

Figure 3 Time trends for yearly prevalence during 2006-2015 in males and females for (A) opioids (N02A), (B) 5HTI agonists/triptans (N02CC), (C) paracetamol (N02BEOI), and (D) NSAIDs (MOIA).

Abbreviation: NSAIDs, nonsteroidal anti-inflammatory drugs. 


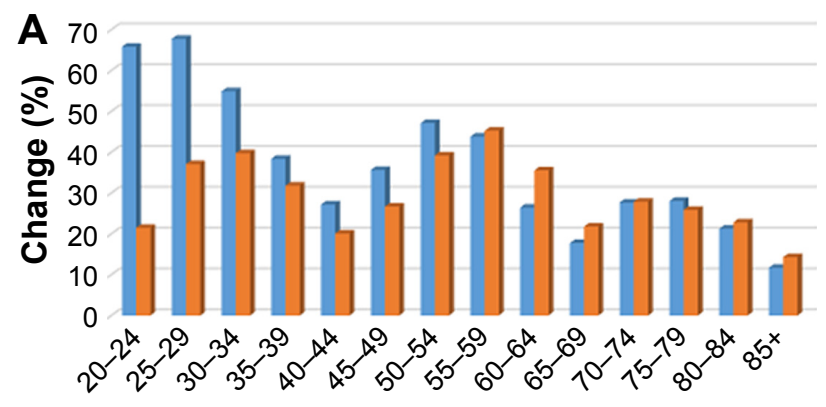

Age groups

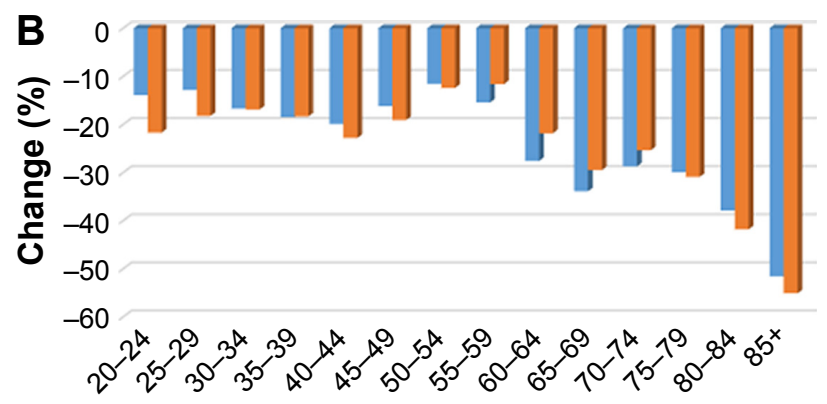

Age groups

\section{Females Males}

Figure 4 Changes (\%) in yearly prevalence between 2006 and 2015 by sex and age group for (A) paracetamol (N02BEOI) and (B) NSAIDs (M0IA). Abbreviation: NSAIDs, nonsteroidal anti-inflammatory drugs.

(N02BE01), this was paralleled by a DDD increase of $38 \%$ for males and 33\% in females (21-29 and 42-56 DDD/1,000 inhabitants/day, respectively). For NSAIDs (M01A), changes in yearly prevalence were paralleled by a DDD decrease of $18 \%$ for males and $26 \%$ in females (34-28 and 54-40 DDD/1,000 inhabitants/day, respectively). Comparing 2006 with 2015, the percentage changes in yearly prevalence in different age groups are depicted in Figure 4A (paracetamol) and Figure 4B (NSAIDs). The group in which paracetamol (N02BE01) dispensations changed most during the decade was in young women (the yearly prevalence increased by two-thirds, Figure 4A); however, in absolute terms, the greatest change occurred in older patients (patients $>75$ years, data not shown; for the yearly prevalence of paracetamol by age group, Figure 2B). For NSAIDs (M01A), the greatest change in dispensations occurred in the older age groups, irrespective of sex; the absolute change of yearly prevalence between 2006 and 2015 was also greatest in the older age groups (similar pattern to Figure 4B).

\section{Discussion}

The major findings of this study were as follows:

- Gender differences in drug utilization are pervasive in Sweden.

- Nine out of 10 subgroups of analgesics/psycholeptics/ psychoanaleptics had a female/male ratio $>1$ for yearly prevalence in 2015.

- Analgesics, including NSAIDs, were investigated closer, revealing a higher female use of drugs in all age groups in 2015 and sustained gender differences over time (2006-2015).

- Gender differences were particularly striking for triptans.
- The yearly prevalence of opioids was stable over time.

- During 2006-2015, the yearly prevalence of paracetamol increased, whereas that of NSAIDs decreased; these changes were most noticeable in young females for paracetamol and in older patients (irrespective of sex) for NSAIDs.

\section{Study limitations}

The limitations of yearly prevalence and DDD as pharmacoepidemiological measures have to be pointed out. Yearly prevalence is a very crude way of measuring drug consumption, as it only reports how many patients per 1,000 inhabitants were dispensed at least one prescription of a particular drug each year. As a particular patient can get different drugs within a given ATC class, yearly prevalence measures cannot be manually added or subtracted. The limitations of yearly prevalence can partially be mitigated by reporting 1) the number of prescriptions per 1,000 inhabitants/year, 2) the number of DDD per 1,000 inhabitants, and 3) by calculating the mean DDD/patient/year and the mean number of prescriptions/ patient/year. These measures are, however, still very crude, and their aggregated nature should be emphasized (ie, this study did not have access to data on an individual level). The limitation of DDD for opioids must also be stressed, as the DDD of different opioids does not take equianalgesic doses into consideration. ${ }^{28}$ Finally, it has to be underlined that this study measured dispensed medicines, not the actual drug intake. Therefore, the study does not, strictly speaking, pertain to drug utilization or consumption. The concept of adherence $^{29}$ is a reminder of the fact that prescription, dispensation, and actual use should not be seen as equivalent.

All these limitations notwithstanding, this study arguably presents valuable information pertaining to 
gender-based differences in drug utilization in the entire Swedish population. Many of the 2015 findings of this study are congruent with results from a previous cross-sectional study from Loikas et al who analyzed data from the Swedish Prescribed Drug Register for 2010.$^{30}$ However, in contrast to Loikas et al, data presented in Table S1 are not age adjusted and they do not refer to the entire population, but only to individuals $>20$ years of age. In the following sections, and in agreement with the aim of the study, only analgesics will be discussed.

\section{Analgesics and the morbidity-mortality paradox}

In 2014, women in Sweden had a life expectancy of 84.1 years, which was almost 4 years longer than men. ${ }^{31}$ This fact, combined with the findings of this study, illustrates the so-called morbidity and mortality paradox: men are more likely to die earlier than women, but epidemiological data show that women have greater self-reported and providerreported morbidity. ${ }^{32}$ The data presented in this paper are congruent with women having a greater self-reported morbidity. Many different factors may underlie gender differences in drug utilization. In the following text, differences in utilization of analgesics will be discussed in more detail.

Conceptually, the following reasons can be hypothesized concerning sex-based differences in the use of analgesics. First, it is well-known that females have a higher propensity for chronic pain. ${ }^{9}$ This could be due to biologic differences in pain processing, for example, putative differences in neural structures ${ }^{9,12}$ or the modulatory effect of sex hormones. ${ }^{9,12,13}$ Recent evidence also suggests that women's higher pain sensitivity may be explained, at least in part, by neuroimmune differences. ${ }^{10,11}$ Moreover, in the context of recurrent menstrual pains and the pain of childbirth, the concept of "latent sensitization" is interesting to ponder. ${ }^{33,34}$ Gender inequalities and gender stereotypes might also lead to differences in levels of psychosocial stress, which in turn might play a role in the development of chronic pain in females compared to males. A related area is sex-related differences in stress response. ${ }^{35}$

Second, another possible reason might be that women are said to have a higher propensity to seek medical treatment, at least in high-income countries. ${ }^{32}$ Hence, all other things being equal, women would tend to seek medical help more often than men. This has, for many years, been claimed to be a rather general phenomenon, ${ }^{32}$ but, focusing on pain, it has been shown that the evidence of greater consultation for back pain and headache among women is weak and inconsistent, especially concerning back pain. ${ }^{36}$ In another study, women contacted their doctor more often than men when experiencing headache, but there was no difference concerning back pain. ${ }^{37}$ Hence, establishing whether women have a higher propensity to seek medical care or not is a difficult matter. Human behavior is, indeed, a complex phenomenon that is influenced by many different factors, and it seems sensible not to generalize or draw strong and definite conclusions. The fact that Swedish women do, indeed, seek medical care more often than men, and that their health care cost per capita in 2004 was $17 \%$ higher than men, ${ }^{38}$ might simply be due to poorer health.

Third, one can ask if there is a higher propensity for physicians to prescribe opioids to women. Indeed, it has been shown that the prescription of drugs might be influenced by the interplay between the sex of the health care provider and patient characteristics. ${ }^{39}$ It has to be remembered that prescription is an outcome of the patient-physician relationship, and that this relationship is a complex psychological and sociological phenomenon. Opioids, triptans, paracetamol, and NSAIDs will be discussed subsequently.

\section{Opioids}

The yearly prevalence of opioids (N02A) was stable over time (2006-2015), with perhaps a slight diminution for females toward the end of the period (Figure 3A). Hence, Swedish physicians do not prescribe opioids to an increasing proportion of the Swedish population. Bäckryd et al have, however, recently shown that this stable prescription pattern hides a dramatic shift in the choice of opioids (ie, "within" the N02A code): the prevalences of tramadol and dextropropoxyphene have gone down substantially (the latter has been pulled off the Swedish market), whereas the prevalences of strong opioids such as oxycodone and morphine have soared..$^{40}$ Although the number of oral morphine equivalents estimated by Bäckryd et al was fairly stable in 2006-2015, the shift from "weak" opioids to "strong" opioids might be problematic from an addiction medicine point of view. ${ }^{40}$ If this is the case, the stable pattern of Figure $3 \mathrm{~A}$ would hide an increasing risk of addiction over time for females.

Some remarks have to be made concerning codeine, methadone, and buprenorphine. Plain codeine, as opposed to its combination products (eg, with paracetamol), is listed outside the N02A opioid group, namely, as a cough suppressant in R05DA04. However, R05DA04 is not widely prescribed in Sweden, its yearly prevalence in 2015 being only 0.8 patients per 1,000 inhabitants. Another opioid that falls outside the N02A group is methadone N07BC02, which is 
used both in opioid dependence and in pain management. The yearly prevalence of dispensed prescriptions of methadone N07BC02 in Swedish pharmacies was low (only 0.56 patients per 1,000 inhabitants). Finally, buprenorphine is placed both in the N02A group (formulations for pain management, N02AE01) and at two places in the N07BC group (drugs used in opioid dependence); N07BC01 and N07BC51 had yearly prevalences of dispensed prescriptions of only 0.18 and 0.13 patients per 1,000 inhabitants, respectively. All in all, plain codeine, methadone, and buprenorphine for opioid dependence are not included in the results presented, but they had low yearly prevalences of dispensed prescriptions and, therefore, are not essential for "the big picture".

\section{Triptans}

The utilization of triptans (N02CC) in Sweden up until 2011 has been previously described; ${ }^{41}$ the present data pertain to a more recent time frame. Sex-related differences were most pronounced for triptans, with the age and sex differences depicted in Figure 2C mirroring well-known differences in migraine prevalence between women and men. ${ }^{42}$ The prescription of triptans (expressed as yearly prevalence) has been stable in Sweden during the last decade (Figure 3B). Sumatriptan was the dominant triptan; its yearly prevalence increased during the decade (7.3-9.5 patients/1,000 inhabitants/year, men and women together, data not shown), whereas the prescription of zolmitriptan and rizatriptan (second and third choice of prescribers, respectively) diminished somewhat.

\section{Paracetamol and NSAIDs}

Traditionally, paracetamol (N02BE01) and NSAIDs (M01A) are seen as "step 1" analgesics on the World Health Organization analgesic ladder. ${ }^{43}$ The Swedish prescription pattern 2006-2015 described herein shows a shift between these "step 1" analgesics, with the yearly prevalence of paracetamol increasing whereas that of NSAIDs decreasing (Figure 3C and D).

The data of this study pertain to what could be called the "post-Vioxx" era. ${ }^{44,45}$ Indeed, not only the use of coxibs, but also certain traditional NSAIDs lead to increased cardiovascular risks. ${ }^{46}$ Naproxen seems to be the safest NSAID from a cardiovascular perspective, but naproxen users may also be at higher risk for upper gastrointestinal bleeding compared to the users of other traditional NSAIDs. ${ }^{46}$ It is not unreasonable to hypothesize that the debate on the safety of NSAIDs in general and of coxibs in particular might have influenced the prescription practice of Swedish doctors. (In contrast, the use of NSAIDs in the USA increased between 2005 and 2010. ${ }^{47}$ ) Increasing age being a well-known factor for NSAID-related side effects, it is interesting to note that changes were more prominent in older patients. Going back to the aim of the study, it is notable that these changes were similar in both men and women (Figure 4B).

Concerning paracetamol, however, changes were most prominent in young women (Figure 4A). Indeed, an additional analysis during the revision stage of this paper revealed that for women 20-24 years of age, dispensed paracetamol (N02BE01) increased from 2.6 to 4.8 DDD/1,000 inhabitants/day during the study period, that is, an increase of $85 \%$ in 10 years. Interestingly, a very recent Swedish survey has shown that adults $<26$ years of age perceived less risk associated with paracetamol use compared with older participants. ${ }^{48}$ There have been concerns that the increased availability of over-the-counter (OTC) paracetamol in non-pharmacy outlets since 2009 might be associated with an observed increase in paracetamol poisoning. ${ }^{49}$ In 2015, the market was re-regulated in the sense that OTC tablets of paracetamol can no longer be sold at non-pharmacies. ${ }^{50}$ The fact that the Pharmacovigilance Risk Assessment Committee of the European Medicines Agency has recently recommended slow-release paracetamol to be removed from the market (because of difficulties in managing overdoses with this modified-release product) is a sobering reminder of the risks associated with this drug. ${ }^{51}$ A limitation of this study is that it included only one source of paracetamol (N02BE01) and not the combination preparations with opioids (in N02A). Additional data on sales of non-prescription paracetamol (and NSAIDs) in Sweden during 2010-2016 were provided by the Network for Pharmacoepidemiology, Linköping University, Sweden (Table S2). In contrast to the trends described for Norway and Germany, ${ }^{52,53}$ OTC sales of paracetamol have been falling since 2013 and were lower in 2016 than in 2010 (Table S2).

\section{Conclusion}

In Sweden, sex differences in drug utilization are pervasive and need to be explored further. Concerning analgesics, this study showed a higher use of drugs by females in all age groups and sustained gender differences over time (2006-2015). Gender differences were particularly striking for triptans. During the last decade, for both men and women, the use of paracetamol increased while the use of NSAIDs decreased. Gender differences in the use of analgesics probably mirror the higher prevalence of chronic pain in women. 


\section{Acknowledgment}

Dr Mikael Hoffmann, head of Network for Pharmacoepidemiology, Linköping University, Sweden, provided data on non-prescription paracetamol and NSAIDs while this paper was being revised.

\section{Disclosure}

The author reports no conflicts of interest in this work.

\section{References}

1. Westerman S, Wenger NK. Women and heart disease, the underrecognized burden: sex differences, biases, and unmet clinical and research challenges. Clin Sci (Lond). 2016;130(8):551-563.

2. Appelman Y, van Rijn BB, Ten Haaf ME, Boersma E, Peters SA. Sex differences in cardiovascular risk factors and disease prevention. Atherosclerosis. 2015;241(1):211-218.

3. Raghavan D, Jain R. Increasing awareness of sex differences in airway diseases. Respirology. 2016;21(3):449-459.

4. Regitz-Zagrosek V. Sex and gender differences in health. Science \& Society Series on Sex and Science. EMBORep. 2012;13(7):596-603.

5. Kuehner C. Why is depression more common among women than among men? Lancet Psychiatry. 2017;4(2):146-158.

6. Buoncervello M, Marconi M, Care A, Piscopo P, Malorni W, Matarrese P. Preclinical models in the study of sex differences. Clin Sci (Lond). 2017;131(6):449-469.

7. Baggio G, Corsini A, Floreani A, Giannini S, Zagonel V. Gender medicine: a task for the third millennium. Clin Chem Lab Med. 2013;51(4): 713-727.

8. Regitz-Zagrosek V, Seeland U. Sex and gender differences in clinical medicine. Handb Exp Pharmacol. 2012;214:3-22.

9. Loyd DR, Murphy AZ. Pain and analgesia. In: Schenck-Gustafsson K, DeCola PR, Pfaff DW, Pisetsky DS, editors. Handbook of Clinical Gender Medicine. Basel: Karger; 2012:183-188.

10. Rosen S, Ham B, Mogil JS. Sex differences in neuroimmunity and pain. J Neurosci Res. 2017;95(1-2):500-508.

11. Sorge RE, Totsch SK. Sex differences in pain. J Neurosci Res. 2017; 95(6):1271-1281.

12. Melchior M, Poisbeau P, Gaumond I, Marchand S. Insights into the mechanisms and the emergence of sex-differences in pain. Neuroscience. 2016;338:63-80.

13. Amandusson A, Blomqvist A. Estrogenic influences in pain processing. Front Neuroendocrinol. 2013;34(4):329-349.

14. Bartley EJ, Fillingim RB. Sex differences in pain: a brief review of clinical and experimental findings. Br J Anaesth. 2013;111(1):52-58.

15. Doyle HH, Murphy AZ. Sex differences in innate immunity and its impact on opioid pharmacology. J Neurosci Res. 2017;95(1-2):487-499.

16. Engel GL. The need for a new medical model: a challenge for biomedicine. Science. 1977;196(4286):129-136.

17. Borrell-Carrio F, Suchman AL, Epstein RM. The biopsychosocial model 25 years later: principles, practice, and scientific inquiry. Ann Fam Med. 2004;2(6):576-582.

18. Wainer J, Wainer Z. Gender matters. In: Schenck-Gustafsson K, DeCola PR, Pfaff DW, Pisetsky DS, editors. Handbook of Clinical Gender Medicine. Basel: Karger; 2012:1-4.

19. Fernandez-Liz E, Modamio P, Catalan A, Lastra CF, Rodriguez T, Marino EL. Identifying how age and gender influence prescription drug use in a primary health care environment in Catalonia, Spain. Br J Clin Pharmacol. 2008;65(3):407-417.

20. Roe CM, McNamara AM, Motheral BR. Gender- and age-related prescription drug use patterns. Ann Pharmacother. 2002;36(1):30-39.

21. Glaeske G, Gerdau-Heitmann C, Hofel F, Schicktanz C. "Genderspecific drug prescription in Germany" results from prescriptions analyses. Handb Exp Pharmacol. 2012;214:149-167.
22. Nishtala PS, Oh S, Kim D, Chun N, Binti Kamis SF, Kiu KC. Analgesic medicine utilization in older people in New Zealand from 2005 to 2013. Drugs Real World Outcomes. 2015;2(2):177-185.

23. Zhong W, Maradit-Kremers H, St Sauver JL, et al. Age and sex patterns of drug prescribing in a defined American population. Mayo Clin Proc. 2013;88(7):697-707.

24. WHO Collaborating Centre for Drug Statistics Methodology. Available from: http://www.whocc.no/. Accessed February 04, 2017.

25. Wettermark B, Hammar N, Fored CM, et al. The new Swedish prescribed drug register opportunities for pharmacoepidemiological research and experience from the first six months. Pharmacoepidemiol Drug Saf. 2007;16(7):726-735.

26. Wallerstedt SM, Wettermark B, Hoffmann M. The first decade with the Swedish prescribed drug register - a systematic review of the output in the Scientific Literature. Basic Clin Pharmacol Toxicol. 2016; 119(5):464-469.

27. Finnerup NB, Attal N, Haroutounian S, et al. Pharmacotherapy for neuropathic pain in adults: a systematic review and meta-analysis. Lancet Neurol. 2015;14(2):162-173.

28. Svendsen K, Borchgrevink P, Fredheim O, Hamunen K, Mellbye A, Dale $\mathrm{O}$. Choosing the unit of measurement counts: the use of oral morphine equivalents in studies of opioid consumption is a useful addition to defined daily doses. Palliat Med. 2011;25(7):725-732.

29. Vrijens B, De Geest S, Hughes DA, et al; ABC Project Team. A new taxonomy for describing and defining adherence to medications. Br J Clin Pharmacol. 2012;73(5):691-705.

30. Loikas D, Wettermark B, von Euler M, Bergman U, Schenck-Gustafsson K. Differences in drug utilisation between men and women: a crosssectional analysis of all dispensed drugs in Sweden. BMJ Open. 2013; 3(5): 002378.

31. Folkhälsomyndigheten. Folkhälsan i Sverige 2016. Halmstad: ISY information system AB; 2016.

32. DeCola PR. Gender effects on health and healthcare. In: SchenckGustafsson K, DeCola PR, Pfaff DW, Pisetsky DS, editors. Handbook of Clinical Gender Medicine. Basel: Karger; 2012:10-17.

33. Pereira MP, Donahue RR, Dahl JB, Werner M, Taylor BK, Werner MU. Endogenous opioid-masked latent pain sensitization: studies from mouse to human. PLoS One. 2015;10(8):e0134441.

34. Tajerian M, Sahbaie $P$, Sun $Y$, et al. Sex differences in a murine model of complex regional pain syndrome. Neurobiol Learn Mem. 2015; 123:100-109.

35. Bale TL, Epperson CN. Sex differences and stress across the lifespan. Nat Neurosci. 2015;18(10):1413-1420.

36. Hunt K, Adamson J, Hewitt C, Nazareth I. Do women consult more than men? A review of gender and consultation for back pain and headache. J Health Serv Res Policy. 2011;16(2):108-117.

37. Elnegaard S, Andersen RS, Pedersen AF, et al. Self-reported symptoms and healthcare seeking in the general population exploring "The Symptom Iceberg". BMC Public Health. 2015;15:685.

38. Socialstyrelsen. Jämställd vård? Könsperspektiv på hälso-och sjukvården. Socialstyrelsen. Stockholm: Swedish Board of Health and Welfare; 2004. Swedish.

39. Deepmala D, Franz L, Aponte C, Agrawal M, Jiang W. Identification of provider characteristics influencing prescription of analgesics: a systematic literature review. Pain Pract. 2013;13(6):504-513.

40. Bäckryd E, Heilig M, Hoffmann M. Dynamiken i forskrivningen av opioider i Sverige 2000-2015 - Markanta omfordelningar inom opioidgruppen, men ingen "epidemi" [Opioid prescription changes in Sweden 2000-2015]. Lakartidningen. 2017;114:EFUE. Swedish.

41. von Euler M, Keshani S, Baatz K, Wettermark B. Utilization of triptans in Sweden; analyses of over the counter and prescription sales. Pharmacoepidemiol Drug Saf. 2014;23(12):1288-1293.

42. Finocchi C, Strada L. Sex-related differences in migraine. Neurol Sci. 2014;35(Suppl 1):207-213.

43. Vargas-Schaffer G. Is the WHO analgesic ladder still valid? Twentyfour years of experience. Can Fam Physician. 2010;56(6):514-517. e202-e205. 
44. Krumholz HM, Ross JS, Presler AH, Egilman DS. What have we learnt from Vioxx? BMJ. 2007;334(7585):120-123.

45. Milerad J. Lärdomar från coxibernas uppgång och fall [Lessons learned from the coxibs' ups and downs. The journals must be tougher against referees and authors]. Lakartidningen. 2008;105(21):1560-1561. Swedish.

46. Quan M. Hot topics in primary care: the cardiovascular safety of nonsteroidal anti-inflammatory drugs: putting the evidence in perspective. J Fam Pract. 2017;66(4 Suppl):S52-S57.

47. Zhou Y, Boudreau DM, Freedman AN. Trends in the use of aspirin and nonsteroidal anti-inflammatory drugs in the general U.S. population. Pharmacoepidemiol Drug Saf. 2014;23(1):43-50.

48. Hakonsen H, Hedenrud T. A population-based study of risk perceptions of paracetamol use among Swedes-with a special focus on young adults. Pharmacoepidemiol Drug Saf. 2017;26(8):992-997.

49. Gedeborg R, Svennblad B, Holm L, et al. Increased availability of paracetamol in Sweden and incidence of paracetamol poisoning: using laboratory data to increase validity of a population-based registry study. Pharmacoepidemiol Drug Saf. 2017;26(5):518-527.
50. Hedenrud T, Hakonsen H. Purchase habits, use of paracetamol, and information sources on a reregulated Swedish pharmacy market: a population-based study. Health Policy. 2017;121(1):35-41.

51. European Medicines Agency. PRAC recommends modified-release paracetamol be removed from market. Available from: http://www. ema.europa.eu/ema/index.jsp?curl=pages $/$ medicines $/$ human/referrals/Paracetamol-modified_release/human_referral_prac_000062. jsp\&mid=WC0b01ac05805c516f. Accessed October 24, 2017.

52. Sarganas G, Buttery AK, Zhuang W, et al. Prevalence, trends, patterns and associations of analgesic use in Germany. BMC Pharmacol Toxicol. 2015;16:28

53. Samuelsen PJ, Slordal L, Mathisen UD, Eggen AE. Analgesic use in a Norwegian general population: change over time and high-risk use The Tromso Study. BMC Pharmacol Toxicol. 2015;16:16.
International Journal of Women's Health

\section{Publish your work in this journal}

The International Journal of Women's Health is an international, peerreviewed open-access journal publishing original research, reports, editorials, reviews and commentaries on all aspects of women's healthcare including gynecology, obstetrics, and breast cancer. The manuscript management system is completely online and includes

\section{Dovepress}

a very quick and fair peer-review system, which is all easy to use. Visit http://www.dovepress.com/testimonials.php to read real quotes from published authors. 